\title{
Processos de projeto de espaços destinados ao livre brincar infantil: interações e experimentações como diálogos entre o designer e o usuário
}

Design processes for childhood free play spaces: interactions and experimentations as dialogues between the designer and the user

NIVOLONI, Graziela; Mestre em Design; Faculdade de Arquitetura e Urbanismo - USP

nivoloni@usp.br

RICCA, Diego; Mestrando em Design; Faculdade de Arquitetura e Urbanismo - USP

diego.ricca.p@gmail.com

MAZZILLI, Clice Toledo de Sanjar; Doutora em Estruturas Ambientais Urbanas; Faculdade de

Arquitetura e Urbanismo - USP

clice@usp.br

\section{Resumo}

Objetiva-se observar aspectos relativos à interação do usuário com o espaço, por meio de sua atividade social e ambiental, a fim de gerar insumos para a prática projetual de ambientes direcionados ao brincar infantil. Parte-se de uma breve contextualização histórica e teórica referente ao ato de projetar, discutindo-o como um processo linguístico e interpretativo, apresentam-se exemplos em que questões de design semelhantes foram aplicadas na prática para, finalmente, discutir experimentos realizados pelos autores durante a pesquisa. Estas dinâmicas se estabeleceram por meio do diálogo e da observação de crianças e permitiram depreender conceitos a partir da interação entre usuário e espaço. Com base nestas análises, conclui-se que o processo de projeto de espaços relativos ao brincar precisa ser repensado e aprimorado por meio da implementação de novas formas de concebê-los com a participação do usuário ou a partir dele.

Palavras Chave: design centrado no usuário; interação; processo de projeto e livre brincar.

\section{Abstract}

The present research aims to observe aspects related to the user's interaction with space, through their social and environmental activity, in order to generate inputs for the design practice of children's play spaces. It begins with a brief historical and theoretical contextualization of the act of projecting, discussing it as a linguistic and interpretative process. Examples are presented in which similar design questions were asked in practice to finally present a research experiment carried out by the authors, which sought, through dialogue and observation of children in the act of playing, the development of concepts from the interaction between user and space. From these analyzes and experiments, it is concluded that the process of designing play spaces needs to be rethought and improved, through the implementation of new ways of conceiving it, with-or by-users participation. 
Keywords: user-centered design; interaction; design process and free play.

\section{Introdução}

A presente pesquisa visa propor reflexões acerca do ato projetual, gerando desdobramentos teóricos que busquem discutir a prática em design e sua relação com aspectos humanos a partir da perspectiva do usuário - crianças entre quatro e cinco anos de idade. Enfocaram-se o processo de projeto, suas condições e possibilidades de experimentação, tomando o ser humano e suas interações com o espaço como elementos estruturadores. O objetivo desta pesquisa é observar aspectos relativos à interação dos usuários entre si e com o meio, por meio de experimentos práticos, a fim de gerar reflexões a respeito da prática projetual de espaços direcionados ao brincar infantil. Alguns fundamentos teóricos do design contribuem para a busca da compreensão da complexa contemporaneidade porque exigem, além de uma ampla e aprofundada análise, que o usuário seja considerado um agente definidor no processo de criação de um projeto.

A fim de situar o usuário não apenas no final do sistema, restrito ao uso do espaço ou artefato, e encará-lo de forma que possa enriquecer o processo projetual, este artigo se inicia com um breve histórico de processos de projeto a partir da década de 1950. Em seguida, dois exemplos práticos serão apresentados como referências para fundamentar esta discussão, visto que foram experiências de intervenções espaciais que estabeleceram seu processo criativo e propositivo a partir da interação entre projetistas, usuários e a comunidade explorando oportunidades de diálogo, escuta, discussão e colaboração. Considera-se, portanto, a observação da interação dos usuários entre si e com o meio, uma importante ferramenta de design. Por fim, apresentam-se os experimentos realizados pelos autores numa Escola Municipal de Educação Infantil (EMEI) da cidade de São Paulo, com o intuito de depreender, a partir da interação social e ambiental de crianças no espaço urbano, algumas considerações de projeto para espaços desta natureza.

\section{Referencial teórico}

\subsection{O humano incluso no processo de projeto}

Nos anos 1950, as abordagens metodológicas, denominadas "design methods movement" (CROSS, 2001; BAYAZIT, 2004), buscaram tratar o ato de projetar de maneira linear e racional, de forma que os problemas de design pudessem ser solucionados a partir de uma sequência de ações, como uma receita que serviria de base para uma infinidade de situações. Conforme Bazjanac (1974), tais modelos projetuais possuíam uma característica em comum: "[...] todos eles viam o processo de projeto como uma sequência de atividades bem definidas e eram todos baseados no pressuposto de que ideias e princípios do método científico podem ser aplicados a ele"1 (BAZJANAC, 1974, p.6). Essa visão lógica e sistemática foi profundamente influenciada pelo pensamento positivista e funcionalista (BROADBENT, 1973/1988; ROWE, 1987).

Esta influência perdeu sua força por volta do final dos anos 1970, quando estes métodos não pareciam mais ser suficientemente eficazes, visto que os problemas da sociedade tornavam-se cada vez mais complexos e heterogêneos e não podiam mais ser solucionados de maneira generalizada e pragmática. Bazjanac apresenta a crítica de que "[...] o design não é um processo estritamente

\footnotetext{
1 Tradução livre do original: "[...] they all view the design process as a sequence of well defined activities and are all based on the assumption that the ideas and principles of the scientific method can be applied to it."
} 
sequencial e os problemas de design são 'capciosos' e um procedimento linear passo-a-passo aplicado a eles não pode, por si só, produzir quaisquer soluções"2 (BAZJANAC, 1974, p.8). Encarar os problemas projetuais sob o viés positivista seria uma forma reducionista de solucioná-los, fundamentando-se, muitas vezes, em uma relação unilateral voltada aos gostos e desejos do projetista, na qual o usuário tem pouca influência ou aparece somente nas etapas iniciais e finais "nas pontas" - deste processo, conforme o gráfico abaixo ilustra.

Gráfico 1 - Representação do posicionamento do usuário em distintos processos de projeto.

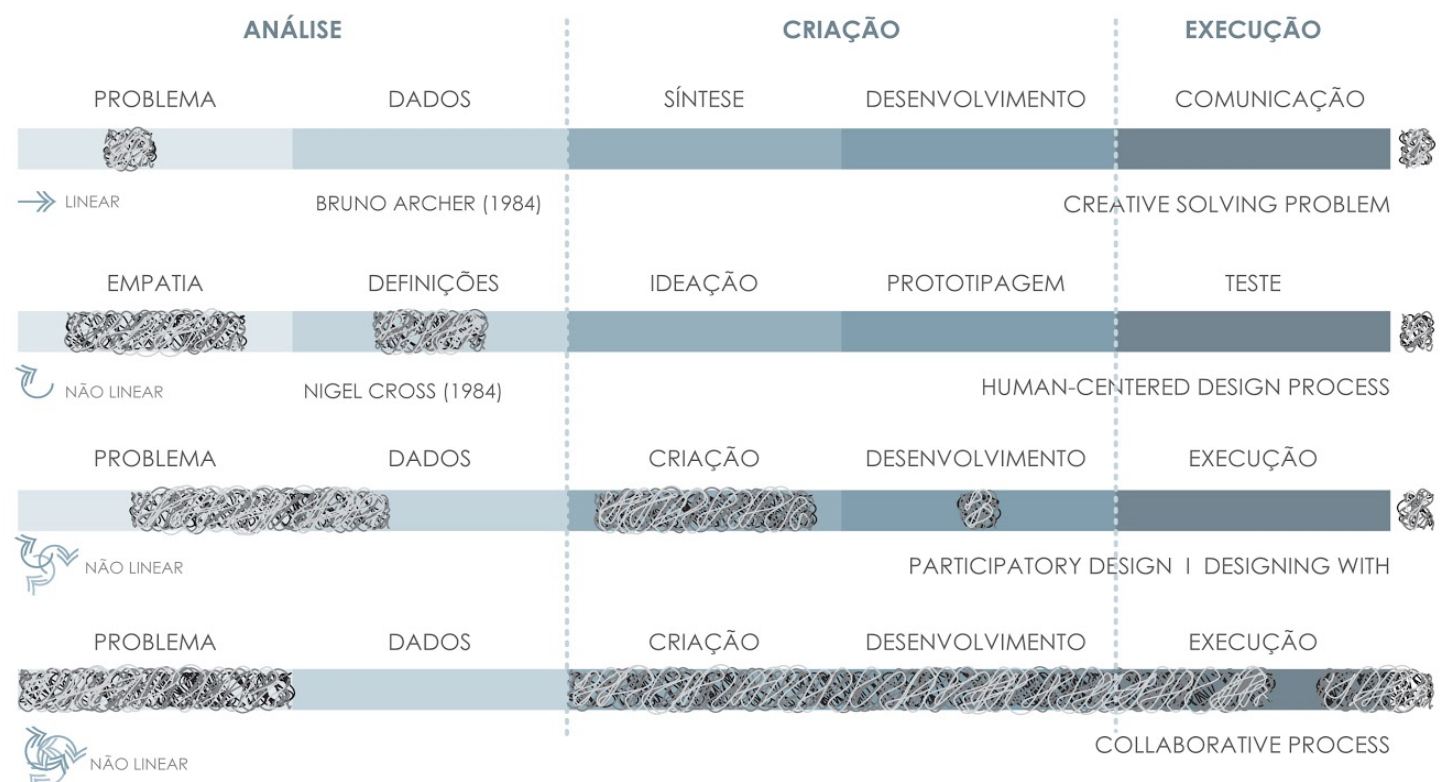

3.8. HUMANO. USUÁRIO. CIDADÃO
CLIENTE. CONSUMIDOR

Fonte: Elaborado a partir de Van Patter, Pastor, 2016 (2018)

A seguir iniciou-se um movimento de inserção de questões subjetivas dos próprios usuários nos processos de projeto, motivo pelo qual a fenomenologia hermenêutica e etnografia começaram a ser estudadas com o intuito de incorporar aspectos relativos à natureza humana. Com base nas obras dos filósofos alemães Martin Heidegger e Hans-Georg Gadamer, os autores Snodgrass e Coyne (2006) trazem uma visão interpretativa do projetar, em contraponto à posição racionalista e cientificista da pesquisa em design, comparando-o com um diálogo no qual o projetista conversa com a situação do problema de projeto.

\subsection{Processo de projeto como linguagem}

Projetar é um processo dialógico, ou seja, não linear e sequencial, mas, cambiante, que se transforma conforme distintas situações e atores (PASCHOALIN, 2014). Intenta-se, por meio deste artigo, discutir conceitualmente o projetar entendendo-o como um processo interativo e argumentativo junto ao problema de design e aos seus respectivos usuários, consistindo em buscar uma solução por meio de "[...] mudar o modo como se percebe a situação 'conversando" (LAWSON, 2011 p.246). Gadamer afirma que a conversação "possui uma força transformadora. Onde uma

\footnotetext{
${ }^{2}$ Tradução livre do original: "[...] design is not a strictly sequential process, and design problems are 'wicked' and a linear step-by-step procedure applied to them cannot by itself yield any solutions."
} 
conversa teve êxito ficou algo para nós que nos transformou" (GADAMER, 1976/1997, p.247). Schon (1983, p.79), apresenta o conceito de projetar como conversação em que designers são levados a refletir a respeito de seus pontos de vista e decisões projetuais a partir do aparecimento de imprevistos e fatos indesejáveis durante o processo. Tais questões eventualmente originam ações e ideias inéditas visto que essa dinâmica em que "o designer transforma a situação de projeto e esta 'responde de volta' transformando o designer" (SCHÖN, 1983, p.150-151). Assim, a tentativa de solucionar um problema pode levar a redefinição do próprio problema, num processo cíclico e não linear que ocorre ao se trabalhar com novos elementos a serem acrescentados durante o processo (CARNEIRO, 2014).

Projetar como processo argumentativo, portanto, associa-se a linguagem como metáfora construção de diálogos, levando a conceitos que relacionam teorias de diversas áreas com a prática do design. Um deles é o conceito interpretativo do círculo hermenêutico, sendo este um símbolo para uma relação interativa e dinâmica entre a compreensão de uma situação projetual e a constante transformação por meio das ações do designer e do usuário (PASCHOALIN, 2012). Este posicionamento do projetista junto ao meio pode gerar consequências não intencionais e novas compreensões por meio de um processo circular de ação e interpretação "procedendo por meio de uma troca dialógica com a situação do design" (SNODGRASS; COYNE, 1997/2006, p.45). Por meio da conversação - entre designer, ambiente e usuários - o ato de projetar ganha progressivamente novos níveis de entendimento e complexidade. Desta forma geram-se novas ideias e soluções por meio da troca constante de informação se o designer estiver atento aos sinais que emergem para interpretá-los. Conforme apresenta Snodgrass e Coyne, "interpretar algo é posicioná-lo dentro de um conjunto de relações" (2006, p.8), e é por meio de experimentos no mundo real que podem ser encontradas respostas. Os autores afirmam que "(...) a compreensão do designer desenvolve-se por uma investigação dialética junto à experienciação da situação do design, a qual considera-se um evento hermenêutico" (SNODGRASS; COYNE, 1997/2006, p.45-46).

\subsection{Interação e desenvolvimento: observando o livre brincar}

Entendendo arquitetura como o conjunto de relações entre ser e lugar, o usuário vive em um "espaço relacional" em conjunto com o ambiente ao seu redor (CABRAL FILHO, 1996). Os seres têm o poder de transformar seu entorno, o que faz com que o espaço adquira um caráter transitório e mutante (ALMEIDA, 2014). Segundo Hugh Dubberly (2009), tal interação é uma forma de tratar da atividade de design, já que todos os objetos projetados "[...] oferecem a possibilidade de interação, e todas as atividades de design podem ser vistas como design for interaction. O mesmo é verdade não só com objetos, mas também com espaços, mensagens e sistemas" 3 (DUBBERLY et al., 2009, p. 69). Vygotsky considera que a atividade do homem no mundo se insere por meio de um sistema de relações sociais, o que sugere que tais aspectos podem ser de grande relevância ao processo de projeto quando analisados segundo critérios que tratam da relação entre duas ou mais pessoas e entre pessoas e artefatos projetados para elas.

Sob a ótica de Leontiev (2004) - discípulo de Vygotsky e precursor da Teoria da Atividade a interação humana com o ambiente é essencial para seu desenvolvimento e aprendizado, em especial na infância. Dentro deste contexto, a atividade humana torna-se uma fonte de coleta para a análise do indivíduo e do ambiente em que este está inserido, como forma de compreender

\footnotetext{
${ }^{3}$ Tradução livre do original: "[...] offer the possibility for interaction, and all design activities can be viewed as design for interaction. The same is true not only of objects but also of spaces, messages, and systems".
} 
aspectos relevantes de construção da consciência e da personalidade (LEONTIEV, 2010; RODRIGUES e CAMPELLO, 2015). É a partir da atividade de interação com o meio que a criança incorpora novas maneiras de pensar sobre o mundo, e desenvolve sua percepção por meio de estímulos externos e conhece novos sabores, texturas, odores, imagens e sons. Na infância, a ação de desbravar o mundo dá-se por meio do brincar como um processo lúdico, em que a descoberta e o aprendizado tornamse um grande jogo, repleto de regras a serem desvendadas, ou até quebradas (MAZZILLI, 2007). Isso sugere que o brincar possa ser definido como importante forma de interação, como processo de autoconhecimento e de atuação no espaço, de manipulação de objetos, artefatos, além da própria interação social junto aos seus pares. Brincar caracteriza-se, segundo Nascimento (2009), como uma “(...) busca pela conquista de autonomia, no sentido da formação de um jeito próprio de perceber o mundo, interpretá-lo, apropriar-se dele e agir, produzindo outros mundos possíveis e resistindo a meios determinantes e pouco criativos de viver" (NASCIMENTO, 2009, p. 36).

As reflexões supracitadas a respeito do processo de projeto visto como um diálogo com a situação, associada à interação - "um produto irrestrito de ambos os participantes, não-direcional (isto é, circular), não causal, sem controle (eventual ou definitivo)" ${ }^{4}$, segundo Glanville (2004) - com o ambiente e seus elementos por meio do ato de brincar pelas crianças, foram experimentadas para fundamentar tais conceitos. A partir da observação dessas situações foi possível perceber seus movimentos e atividades, além de estabelecer uma análise aprofundada que culminou na elaboração de algumas considerações que possivelmente contribuirão para a prática de projetos voltados ao livre brincar infantil.

\section{Referências para as experimentações}

\subsection{Interações com usuários: Grupo Boa Mistura}

Ao contrário do que se discute sobre o conceito de interação, frequentemente reduzido à relação humana com interfaces digitais (homem-computador), há muitos outros aspectos a serem considerados visto que o homem é, por natureza, um ser interativo e se relaciona continuamente com pessoas, com seu entorno, com ambientes construídos e com artefatos em geral. Ao longo de seu processo de desenvolvimento, as pessoas interagem com o espaço de distintas formas ao longo de suas vidas, em diversas escalas e facetas (CARNEIRO, 2014). Estas relações com o ambiente e com as pessoas ao seu redor se dão por meio de seus sentidos e é, a partir deles, que se inicia o processo de conhecimento do espaço-ambiente. Utilizando-se desta estratégia, o grupo Boa Mistura, formado por uma equipe multidisciplinar, realiza intervenções urbanas por meio de pintura, seja em fachadas de prédios, vielas de comunidades (favelas), pisos, muros, com o intuito de melhorar esteticamente os espaços e modificar a forma como as pessoas os percebem e como se relacionam com eles (BOA MISTURA, 2017).

O Boa Mistura credita à pintura - uma técnica simples, de baixo custo, fácil manutenção e acessível a todos - a capacidade de evocar emoções nas pessoas, torná-las partícipes do processo, coautoras da transformação, capazes de mudar seu entorno, para mudar a relação delas com seu lugar e conectá-las de alguma forma entre si. Realizam-nas potencializando os conceitos de comunidade, convivência e colaboração, inspirando-as com palavras positivas, grafismos e padrões

\footnotetext{
${ }^{4}$ Tradução livre do original: "an unconstrained product of both participants, is non-directional (i.e. circular), non-causal, without (eventual or ultimate) control".
} 
relativos àquilo que já existe no local, e que merecem ser expostos para que tais valores sejam reafirmados, evitando que sejam desvalorizados ou esquecidos.

\begin{abstract}
É essencial em nosso trabalho que o resultado se identifique de alguma maneira com o lugar e com as pessoas que lá vivem, para que possa realmente haver uma troca e entre nós e eles. Para chegar nisso, é muito importante que os habitantes do bairro se sintam partícipes das tomadas de decisões o projeto e sejam, em parte, autores da obra. (BOA MISTURA, 2017)
\end{abstract}

É na busca por provocar emoções positivas nos usuários destes espaços que o processo de projeto deste grupo não se fundamenta em um padrão estabelecido, e se desenvolve a partir do momento que chegam ao local e começam a vivenciá-lo e compartilhá-lo com as pessoas que ali residem. A partir desta interação, iniciam a construção de vínculos e começam a identificar com os usuários se relacionam com este lugar, como o percebem, quais suas especificidades, suas "manifestações culturais mais características" (BOA MISTURA, 2017). Juntamente com as observações e percepções dos integrantes da equipe, começa-se a pensar em possibilidades de intervenção no espaço. As ações são, portanto, realizadas em conjunto com os usuários, sendo um meio de reforçar um estabelecimento de relações afetivas das pessoas com o ambiente que as cerca. Don Norman (2008) considera que além das formas físicas e funções sociais, os objetos assumem formas sociais e funções simbólicas (NORMAN, 2008). Desta forma é possível projetar objetos ou intervenções espaciais - a fim de proporcionar experiências prazerosas e desencadear sentimentos positivos nos usuários.

\title{
3.2 Estimulando e observando as interações: Experimental Playground
}

Observar as crianças brincarem para gerar subsídios para o ato projetual, pode oferecer ferramentas para que interações com o espaço sejam mais ricas, permitindo que uma maior quantidade de dados possa ser coletada para um processo de design mais próximo dos usuários. Um exemplo que se destaca na aplicação de tais conceitos deu-se no projeto da área externa pertencente à Daubeney Primary School em Londres. Intitulado "Experimental Playground", este projeto, realizado pelo escritório Kinnnear Landscape Architecture em 2000, foi publicado no site Designing with children (THANE, 2005). Nesta experiência as crianças não são tidas apenas como usuárias de um produto finalizado, e sim, como colaboradoras do processo de projeto, a partir de suas ações e proposições. Este processo de projeto da arquiteta Lynn Kinnear teve sua fase de coleta de dados dividida em quatro fases, as quais foram documentadas em vídeo (THANE, 2005). Jacobs (2011) defende que um projeto não deve ser estruturado - sejam quais forem suas especificidades ou restrições - única e exclusivamente em conhecimento explícito e declarado, ou em premissas e preceitos teórico-conceituais estabelecidos. Cidades, espaços e artefatos devem, portanto, ser pensados e propostos após profunda observação (JACOBS, 2011) e a partir de quem os pratica cotidianamente (JACOBS, 2011). A arquiteta Lynn inicia a primeira fase de coleta com uma atividade no espaço livre da escola, sem o uso de nenhum artefato para estímulo das interações, e antes de qualquer intervenção projetual, a fim de iniciar o seu processo de observação a partir do cotidiano natural das crianças. Ela mapeia e interpreta as interações ali realizadas descrevendo brevemente

\footnotetext{
5 Tradução livre do original: "Es esencial en nuestro trabajo que el resultado se identifique de alguna manera con el lugar y con la gente que vive en él, para que pueda realmente hacer un cambio y relacionarse con ellos. Para lograrlo, es muy importante que los habitantes del barrio se sientan partícipes de la toma de decisiones para el proyecto y en parte autores de la obra".
} 
as dinâmicas mais frequentes. Desta forma ela busca entender o que significam os gestos e as expressões a fim de propor padrões ou aproximações preliminares de premissas projetuais.

A segunda etapa de coleta caracterizou-se pela disponibilização aos usuários de alguns elementos que lhes permitissem intervir no espaço, dentre estes foram utilizados inúmeros suportes, tais como: cones de trânsito, pequenas estruturas de madeira semelhantes a paletes para transporte de mercadorias e giz para desenhar o/no piso. A partir destes estímulos, as crianças foram modificando o espaço à sua maneira, criando obstáculos, padrões, desafios, cabanas, desenhos no piso, plataformas e jogos. Lynn Kinnear buscou avaliar e observar como as próprias crianças criaram brincadeiras, geraram e transformaram os espaços, construíram situações de interação.

A partir desta dinâmica, princípios e premissas projetuais foram estabelecidos. Contando com uma verba restrita, foram recriadas, de maneira distinta, várias das possibilidades aventadas pelas próprias crianças. Alguns elementos foram, portanto, inspirados nos dados coletados anteriormente, os quais foram implantados com sucesso pela arquiteta no espaço livre da escola. Dentre estes elementos propostos estão: 1) mudança na topografia do local gerando volumes para o desafio de escaladas e descidas; 2) aplicação de superfícies refletoras em uma das laterais do espaço para oferecer chances de se observarem em movimento e articular duas áreas de jogos; 3) pintura no piso, por meio de faixas coloridas e brancas distribuídas com espessuras e espaçamentos variáveis e as grandes faixas de pedestres ("oversized zebras") para demarcação de campos, criação de fluxos de movimentações distintas, possibilidade de criação de jogos a serem inventados ou reinventados - como a amarelinha modificada -, brincadeiras de gerar circuitos e, até mesmo, a possibilidade de recriar o espaço urbano para gerar situações de educação e segurança no trânsito; 4) instalação de pequenas plataformas giratórias que podem ser movimentadas pelas próprias crianças e que permitem conformar um grande círculo, grandes plataformas lineares, ou pequenos agrupamentos que estimulam atividades de equilíbrio e desafio, jogos e circuitos, além de atividades musicais com as pisadas ritmadas, rodas de conversas e contação de estórias em grupos de até 25 crianças; 5) postes metálicos foram instalados conformando uma retícula ou grid, forest of poles, com ganchos para tecidos e lonas, que podem ser instalados, conectados ou retirados conforme o desejo, e permitem a modificação concreta do espaço, dando autonomia às crianças que os exploram com a criação de cabanas e abrigos, bastante favoráveis às brincadeiras de faz-deconta, imaginação, leitura de livros, conversas secretas, jogos de esconde-esconde e pega-pega, labirinto etc.

Em resumo, foram criadas oportunidades e dinâmicas de naturezas distintas como atividades motoras relacionadas a velocidade, desafio, força e equilíbrio, brincadeiras de faz-de-conta e imaginação, jogos em grupos e situações de aprendizagem fora da sala de aula. Esta intervenção foi capaz de diminuir substancialmente brincadeiras agressivas que frequentemente terminavam em brigas, bem como, atribui-se às alterações no espaço melhorias no rendimento escolar e na concentração dos alunos (THANE, 2005).

\section{Experimentos para coleta de dados: Interações no Glicério}

A partir de preceitos relativos ao ato de interação associados ao livre brincar, realizaram-se experimentos para observar os usuários mais de perto, sem interferir, com o mínimo de expectativa possível (JACOBS, 2011). Ouvir as crianças, perceber seus repertórios formais e visuais, suas vivências e suas experiências relacionadas à cidade e ao espaço público, como oportunidades de 
aprendizado sobre o que elas buscam, como exploram os espaços e deles se apropriam. Como crianças podem participar de forma efetiva da concepção projetual de espaços voltados ao brincar?

Os experimentos foram realizados em uma Escola Municipal de Educação Infantil (EMEI) da região central da cidade de São Paulo: Glicério, uma área de baixa renda com crianças entre quatro e cinco anos que vivem em condições precárias de moradia ou em situação de cortiço. Tal escolha de idade se deu por serem aquelas cuja aprendizagem dá-se, essencialmente, pela educação nãoformal, ou seja, por meio de experiências e vivências de interação social e ambiental, ou seja, por meio do livre brincar. Segundo Winnicott (2005), trata-se de uma faixa etária em que os seres humanos possuem um modo de existir em si mesmo, e se relacionam-se com outros seres vivos e objetos como a si mesmo, além de passarem por acentuado desenvolvimento cognitivo, físico, emocional e de linguagem.

Figuras 1 e 2 - Localização do experimento na zona central da cidade de São Paulo, Brasil.
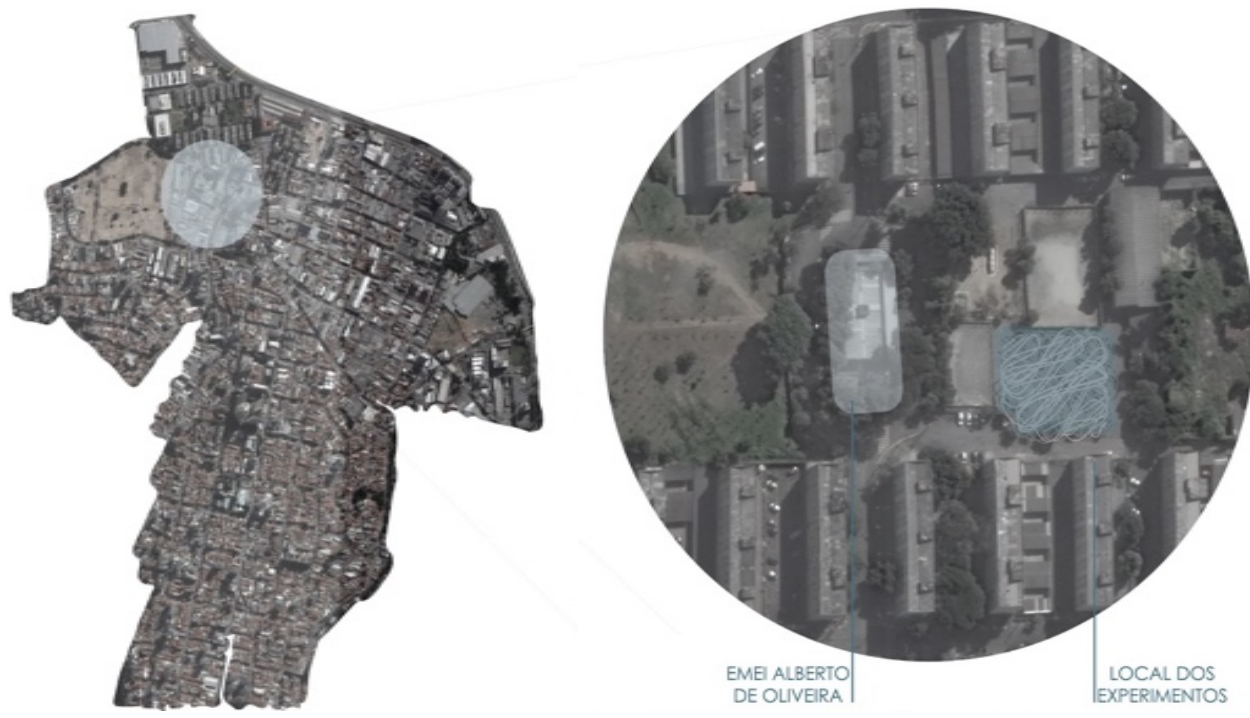

Fonte: Acervo dos autores (2017)

Figuras 3 a 7 - Imagens do local onde os experimentos foram realizados.
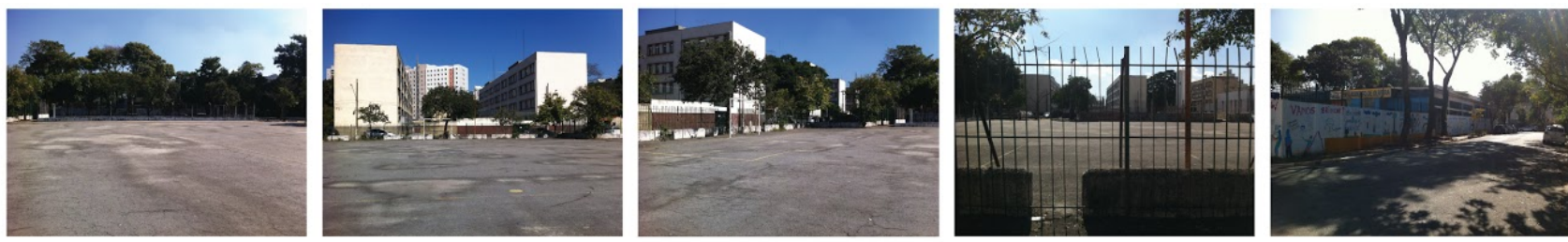

Fonte: Acervo dos autores (2016)

Os registros foram realizados por meio de câmeras fixas, de visão geral, e móvel, aplicada a um capacete infantil de bicicleta usado pela criança que se dispusesse fazê-lo voluntariamente e pelo tempo que quisesse com o intuito de obter, sob sua perspectiva, a maneira como ela apreende o espaço, como interage com ele, com seus elementos e com as outras crianças (imagem abaixo). Esta possibilidade de filmagem sob vários pontos de vista revelou-se de fundamental importância, como pode ser visto com a conexão dos vídeos gerados, concomitantemente de pontos distintos - 
pesquisador-observador e criança-usuária. A relevância de experimentar, de alguma forma, o olhar da criança, pode ser descrita a partir de Klisys (2010) durante uma dinâmica vivenciada pela autora em que pais, filhos e educadores construíam, a partir de papelão, sucata e restos de materiais um foguete: no momento de aplicar o papel laminado em quantidade insuficiente para o revestir integralmente, iniciou-se um embate entre adultos e crianças. Os adultos queriam aderi-lo externamente, já as crianças defendiam enfaticamente que deveria ser aplicado no lado de dentro do foguete. Esta discussão nos mostra que o adulto tem a visão de observador, enquanto a criança tem o "ponto de vista de quem vai participar da brincadeira e, portanto, vai estar a maior parte do tempo dentro da nave"(KLISYS, 2010). Tal situação, ainda segundo a autora, "demonstra o quanto têm escapado ao nosso olhar as sutilezas da forma como a criança concebe seu espaço para o brincar e o quanto temos que aprender a incluir mais o seu ponto de vista" (KLISYS, 2010).

Figuras 8 e 9 - Printscreen da tela dos vídeos gerados concomitantemente, durante o segundo experimento, pelas duas câmeras usadas para registro, sendo a imagem da esquerda a visão geral do observador-pesquisador e a da direita, a perspectiva de uma das crianças.

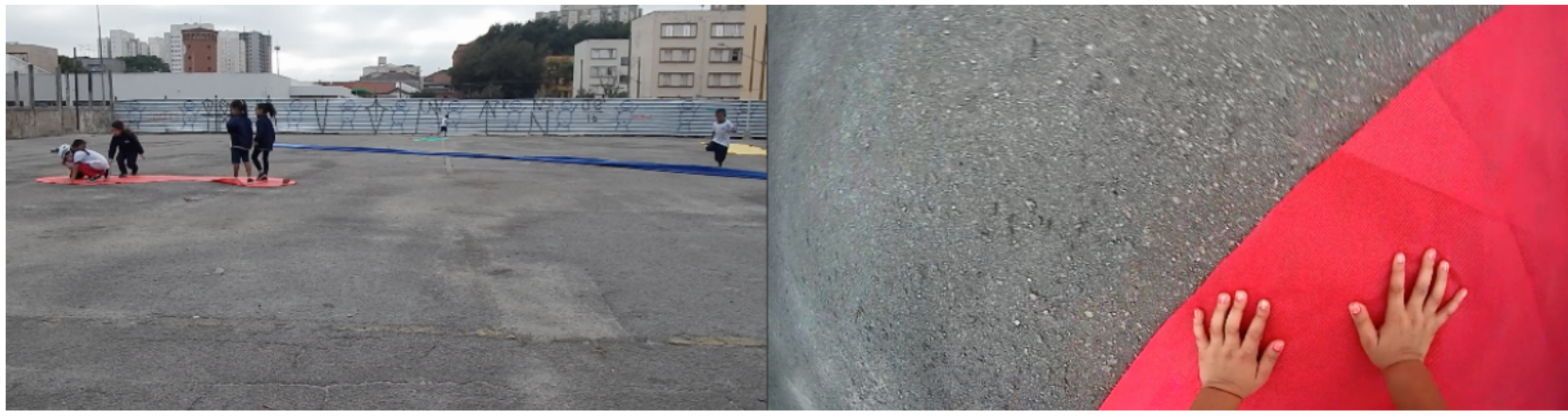

Fonte: Vídeos elaborados pelos autores, com base na pesquisa realizada (2016)

Os experimentos foram divididos em cinco atividades, além de oficinas lúdico-participativas. Na primeira dinâmica desenvolvida, o espaço não sofreu qualquer intervenção física e elas foram convidadas a brincar livremente durante a qual, as crianças iniciaram a exploração do espaço, correndo em círculos e organizando-se, sem regras claras e definidas, em grupos e, por vezes, brincando de fugir e pegar. Depois de algum tempo, após a diminuição da euforia, começaram a experimentar o espaço e seus elementos, a conversarem mais entre si e discutir outras formas de brincar como subir nas grades, escalar estruturas pré-moldadas de concreto e atirar pedras.

No segundo experimento, foram utilizados, pedaços coloridos de tecido-não-tecido (TNT), recortados como manchas de cor, aplicados com cola no piso, em formas não-geométricas para observar e analisar como as crianças passariam se relacionar com o espaço e seus novos elementos, como se articularam entre si e se surgiriam, em algum momento, brincadeiras ou jogos a partir deles e todos transformaram de alguma maneira sua dinâmica eufórica de fruição do espaço.

Inspirado no experimento realizado por Willett (2014) a respeito da criação de jogos e brincadeiras por meio de bambolês aplicados no piso durante o recreio em uma escola, pelas próprias crianças - segundo preceitos de design denominado bricoleur ${ }^{6}$ - foram oferecidos sessenta

\footnotetext{
${ }^{6}$ Segundo Elvira de Almeida (1977) - termo empregado a partir de Lévi-Strauss (1976) em suas reflexões sobre o pensamento selvagem, de caráter mítico e poético - consiste num processo produtivo e criativo, aberto às experimentações e à lógica sensível de se construírem "novas realidades" (ALMEIDA, 1977, p.34) com o que se tem à
} 
bambolês aos alunos. Depois da euforia inicial que os contagiava e os impelia a correr freneticamente pelo espaço - num movimento ansioso de fruição - foi observado com maior frequência o uso convencional do brinquedo, sendo este o uso em movimentos circulares do bambolê em volta da cintura ou articulações do corpo. Decorridos aproximadamente seis minutos, uma criança sugeriu a outras quatro meninas: "Vamos fazer uma trilha?", em tom empolgado. As crianças convidadas para tal dinâmica começaram a recolher os bambolês inutilizados, pois alguns haviam sido devolvidos por crianças que não enxergaram outras possibilidades de uso e que preferiram voltar a correr e explorar o espaço. Desta forma, conseguiram organizá-los como uma grande travessia envolvendo aproximadamente trinta e cinco bambolês. Crianças que não participaram da construção participaram da brincadeira de formas variadas, correndo, pulando, andando e atravessando a trilha perpendicularmente. Aquelas que construíram, realizaram um exercício de projeto e construção colaborativa, levantando ideias, criando respostas, inventando narrativas. Klisys (2010) cita a construção da brincadeira como um fim em si como uma parte muito negligenciada por quem projeta ou propõe espaços destinados ao brincar infantil. Durante a dinâmica, foram inúmeras as situações construídas pelas crianças considerando interferência no espaço, em especial no piso, afinal, cada reorganização dos bambolês sugeria novas explorações.

O brincar pode ser considerado uma forma de manifestação cultural construída, como uma linguagem (FRIEDMANN, 2011). Desta forma outras dinâmicas, que não se construíam a partir ou por meio do espaço, foram desenvolvidas. Um dos exemplos aqui destacados é o ato de "vender" bambolês ou usá-los como representação de sorvetes anunciando os sabores de acordo com suas cores e os valores gritando: "Quem quer sorvete de uva? Sorvete de uva!" Outra atividade recorrente relativa ao desafio, força e habilidade, foi jogar o bambolê para o céu com força e observá-lo cair e se locomover de maneira inusitada quando toca o piso e empurrá-lo junto ao piso, girando com força, para ver se deslocar e correr ao seu lado. Também foi comum observar as crianças correndo com bambolês junto ao corpo, manipulando-os de formas variadas na busca por compreender como se relacionam com o objeto, como se movimentam no espaço. Essa dinâmica, entre inúmeras e valiosas informações, nos mostra a vontade de manipular elementos e o espaço que os contém, a busca incessante e ansiosa por explorar, experimentar e interagir por meio do brincar. Novamente elas tiveram a oportunidade de criar suas próprias brincadeiras, o que se mostrou bastante efetivo, no sentido de haver um retorno de prazer e alegria observado nas feições e gestos dos usuários.

As crianças que se encarregaram por construí-la, realizaram evidentemente, um complexo exercício de projeto por meio de construção colaborativa na qual discutiam onde colocar os bambolês, aplicando-os de uma forma, mudando sua posição, discutindo ideias, criando respostas e buscando soluções, definiram, além das disposição e localização dos bambolês, as cores e a ordem em que deveriam ficar. Além disso, inventaram narrativas a fim de responder com tais objetos às suas vontades e desejos: "Vamos fazer um caminho!", "Estamos brincando que estamos perdidos e este é o caminho que volta para casa." O empenho e a colaboração, com a qual construíram esta situação lúdica, chamaram atenção e, em questão de dois minutos, a brincadeira já possuía regras em relação ao início, ao sentido de uso da trilha, como deveria ser trilhada, restrições e impedimentos etc. Klisys (2011) cita a construção da brincadeira como um fim em si e, portanto,

mão e com aquilo que se sabe fazer. Pressupõe que tal prática “[...] possibilita a construção de outros 'mundos' com restos, vestígios, lembranças, operando sempre com qualidades de ocasião, conveniência ou possibilidades mais ou menos aleatórias" (Ibid., p. 34). 
aponta ser comum as crianças passarem a maior parte do tempo fazendo elaboradas cabanas, desmontando-as e refazendo-as de várias maneiras distintas, num processo semelhante às experimentações projetuais, ou montando a casa da boneca por completo, e, quando chegaria a hora de iniciar a brincar, desistem da brincadeira. São relatos da autora que denotam se tratar de uma parte muito negligenciada por quem projeta ou propõe espaços destinados ao brincar infantil: a elaboração, a criação, a construção e a realização pelas próprias crianças. Um dos fundamentos da brincadeira é prepará-la, conforme afirma Klysis (2010): "não é à toa que meninas passam horas arrumando o mobiliário de casinha de bonecas e meninos, organizando cenários para seus superheróis contracenarem. O preparo em si já faz parte da brincadeira. (KLYSIS, 2010, p.104). Durante a dinâmica, foram inúmeras as situações construídas pelas crianças considerando interferência no espaço, em especial no piso, afinal, cada reorganização dos bambolês sugeria novas explorações e foram quatro composições conformando caminhos. Como a quantidade de bambolês era muito grande e a facilidade com que eram manipulados, elas foram capazes de construir a brincadeira, desconstruí-la e reconstruí-la de outras formas, o que lhes permitiu, portanto, qualificarem efemeramente o espaço, do qual apropriaram-se verdadeiramente. Por meio de medições, realizadas conforme o tempo e quantidade de crianças, estas dedicaram-se mais ao ato de construir tais caminhos, do que vivenciá-los, num total de sete crianças percorrendo-os e nove fazendo-os em dois momentos registrados.

A atividade posterior deu às crianças a possibilidade de desenhar no piso. Na primeira elas foram convidadas a desenhar com giz, como gostariam que aquele espaço público - degradado, pouco utilizado por pessoas e sem equipamentos - fosse. Foi perguntado o que elas gostariam de ver naquele local, que elementos, tratamentos e equipamentos gostariam que houvesse.

$\mathrm{Na}$ atividade final, foram oferecidos rolos de durex colorido para que as crianças modificassem o espaço aplicando-o ao piso, com o intuito de criar algo com que pudessem brincar. Algumas crianças trabalharam em equipe e algumas sozinhas, porém todas buscavam algo. Dentre as manifestações observadas, os usuários seguiam vontades, intuições e desejos na criação de uma nova espacialidade. Em um nítido exercício projetual sobre como lidar com o material, surgiram questionamentos a respeito das limitações e possibilidades do uso do durex, bem como, o que poderiam exteriorizar a partir dele: quais soluções e formas adotar? Como construir o que se pretende? É possível notar, pelos gestos, olhares e o afinco com que se dispunham a manipular os artefatos ofertados para desenvolver novas formas de brincar, que as crianças querem, interessamse e se dispõem, com prazer a fazê-lo, apropriar-se de do espaço e de seus elementos, explorá-lo com o que se tem em mãos e vivenciá-lo da forma mais intensa possível, por meio do brincar (MOORE, 2015). Moore (2015) relata que, por meio destas oportunidades, as crianças têm fortalecidos "seus laços emocionais e de identidade com estes espaços" 7 (p. 26).

A partir destas faixas de cor, foi possível observar as crianças interagindo com o espaço de formas distintas, respondendo de alguma maneira aos estímulos criados por elas próprias. Somente algumas composições foram nomeadas por elas como trilho do trem ou pista de skate, porém todas foram, de alguma forma, exploradas pelas crianças, como pode ser visto na sequência de imagens abaixo, em que um dos meninos (vestindo a camiseta vermelha) levanta-se olhando para o piso, entusiasmado para experimentar o que acabou de construir. O registro desta situação se deu por uma outra criança - com a câmera instalada em seu capacete - que observou com atenção e

\footnotetext{
7 Tradução livre do original: "their emotional attachment to their places".
} 
interesse o que acontecia. Depois do período de construção e experimentação, elas permaneceram no espaço para brincar livremente e foi possível observar que a maioria das crianças correu pelo espaço brincando de pega-pega e interagindo com as fitas, buscando alinhar suas trajetórias às linhas coloridas do piso ou percorrendo-as, abrindo os braços em busca do equilíbrio.

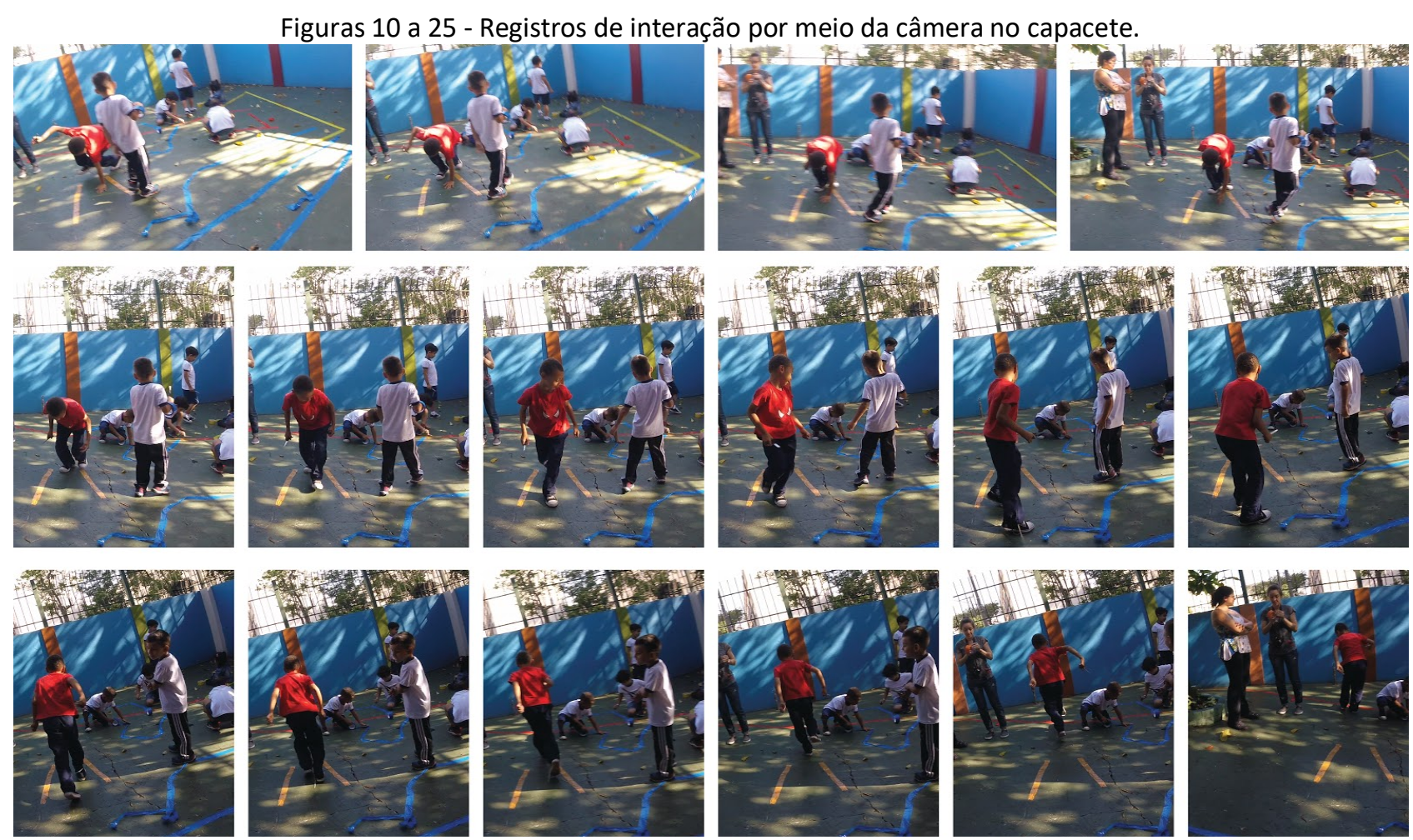

Fonte: Vídeos elaborados pelos autores, com base na pesquisa realizada (2016)

\section{Resultados (considerações finais)}

A concepção destas atividades com crianças como oportunidades de interação e diálogos para compreendê-las mais profundamente foi estabelecida como um processo dinâmico de indagações exploratórias, nas quais os experimentos e seu processo projetual não estavam definidos por completo. Adotou-se, segundo a Antropologia das Infâncias (FRIEDMANN, 2011), uma perspectiva fluida, múltipla e não estática, cujas práticas foram repensadas e algumas propostas reelaboradas com e a partir das vozes das crianças, de suas buscas e necessidades (FRIEDMANN, 2011). Trata-se de um processo de coleta de dados harmonizado com as questões complexas da contemporaneidade: flexível, holístico, afeito à intuição, sem planejamento integral e suficientemente aberto a explorações. É o que Sevaldson (2000) chama de open-ended investigations ou not-always-knowing-what-we-are-doing.

A pesquisa pela observação da ação, gestáltica por natureza segundo David Gray (2004), é uma forma de encorajar mudanças sociais por meio de um reconhecimento científico do valor do experimento para a criação de conhecimento. Talvez esta relação entre quem projeta (designer) e para quem se projeta (as crianças) possa ser encarada como um fortuito diálogo, como articulou-se neste artigo por meio das experimentações e oficinas lúdico-participativas em que, conforme pressupõe Klisys (2010), "a resposta depende do adulto e de como ele vê a criança", pois ela ainda é vista como um ser em formação, incompleto, incapaz, "um vir a ser" (KLISYS, 2010, p.69). Nestas 
interações, elas foram encaradas como parceiras que instigaram a repensar conceitos, desconstruir paradigmas com um "ponto de vista inaugural, não habitual, não acomodado, com a sensibilidade afinadíssima e em consonância com seus desejos" (KLISYS, 2010, p. 69).

Considerar processos mais abertos e colaborativos, novos métodos e ferramentas, um olhar mais cuidadoso e sensível às lacunas e vazios entre o profissional e o usuário, seja talvez apenas o início de uma trajetória em que ambos devam conviver mais, estabelecer vínculos, aproximar repertórios e olhares (GLENN et al., 2013, NICHOLSON et al., 2014), com o intuito de trazer mais elementos para este sistema, novas formas de elaborá-lo e considerar a criança de modo mais presente e ativa, em "que as duas partes ensinam e aprendem, não se sobrepondo uma à outra. Há interesse mútuo e respeito pelo modo de cada um se expressar." (KLISYS, 2010, p.69). Nos exemplos explicitados e nos experimentos realizados, notou-se que muitas das atividades seguiram como planejado, mas que as crianças também perceberam atributos que não foram previstos pelos projetistas. Também foi possível observar que elas usaram a maior parte do tempo explorando e criando suas próprias situações lúdicas, avançando nas proposições ofertadas o que evidencia, conforme Morrisey et al. (2015), que ainda há muito a aprender com a forma como as crianças experienciam o mundo. Essa análise tem muito a contribuir com o processo projetual de espaços recreativos infantis (MORRISEY et al., 2015) e denuncia a falta de oportunidade das crianças exercitarem ação transformadora e de se sentirem sujeitos, como a Antropologia das Infâncias pressupõe. Durante as experimentações e interações, as falas das crianças mostraram a capacidade inventiva que possuem, o que buscam, como percebem a cidade e como gostariam que esta fosse mais aberta ao brincar.

Quando se projeta um espaço, a percepção da criança - o usuário em questão - fica subjugada no processo criativo. Ainda que o arquiteto ou designer busque apreender o campo visual da criança deslocando-o para baixo, a uma altura aproximada de 95 centímetros, ele não busca compreender de forma sensível o seu repertório formal e visual, a maneira como ela observa e se relaciona com os espaços, seus elementos e outras crianças. Para que os espaços destinados ao brincar estejam abertos à vontade de manipular, criar, transformar e experimentar delas, o processo de projeto de espaços desta natureza precisa ser repensado por meio da implementação de novas formas de concebê-los, com a participação dos usuários ou a partir deles. Nota-se, a partir dos resultados deste artigo, que muito tem escapado aos olhos de quem propõe espaços e equipamentos relativos ao brincar, pois frequentemente, os infantes percebem atributos que não foram previstos pelos projetistas.

Informações a respeito de novos processos que tragam dados sobre o que buscam as crianças e o que as move genuinamente não estão sendo, via de regra, considerados durante a criação dos arquitetos e designers. Portanto, conclui-se que romper paradigmas implica em tornar o processo projetual mais democrático e sensível às pessoas, conforme Margolin e Manzini defenderam em manifesto publicado em 2017 a respeito da relação entre democracia e design no qual afirmam categoricamente que projetar de forma "normal" não é mais suficiente. É importante, segundo eles, que a comunidade de Design posicione-se a favor da democratização do projeto, e que, portanto, oportunidades mais ricas e aprofundadas de ações que fomentem o bem-estar coletivo possam ser instauradas e construídas. Este artigo consiste numa tentativa de reflexão sobre o tema e considera essencial o exercício do diálogo em design com mais interação entre os espaços e os humanos para os quais se projeta: "[...] precisamos fazer mais, agora, do que apenas projetar de forma "normal" (MARGOLIN, MANZINI, 2017). 


\section{Referências}

ALMEIDA, M. A. de. Ambientes interativos: a relação entre jogos e design para a interação - Tese de Doutorado. Belo Horizante, Minas Gerais: Universidade Federal de Minas Gerais, 2014.

BOA MISTURA. BOA MISTURA: depoimento [outubro de 2017]. Entrevista cedida aos autores.

CABRAL FILHO, José dos Santos. Formal games and interactive design: computers as formal devices for informal interaction between client and architects. Sheffield: Sheffield University, 1996.

CARNEIRO, G. P. Arquitetura Interativa: contexto, fundamentos e design - Tese de Doutorado. São Paulo: FAU-USP, 2014.

DUBBERLY, H.; PANGARO, P.; HAQUE, U. What is interaction? Are there different types? Interactions, Jan-Fev de 2009: 69-75.

FRIEDMANN, Adriana. Paisagens infantis: uma incursão pelas naturezas, linguagens e culturas das crianças. Tese de Doutorado em Ciências Sociais. São Paulo, Pontífica Universidade Católica de São Paulo PUC-SP, 2011.

GADAMER, H. G. Verdade e método. Traços fundamentais de uma hermenêutica filosófica. Tradução Flávio Paulo Meurer. Petrópolis, RJ: Ed. Vozes, 1975/1997.

. Verdade e método II. Complementos e índice. Tradução Ênio Paulo Giachini. Petrópolis, RJ: Ed. Vozes, 1976/2002.

GLENN, N. M., KNIGHT, C. J., HOLT, N., SPENCE, J. C., Meanings of play among children. In Journal Childhood, 20(2):185-199, 2013.

GRAY, D. Doing research in the real world. London, SAGE Publications, 2004.

JACOBS, Jane. Morte e vida das grandes cidades. São Paulo: Editora WMF Martins Fontes, 2011.

KLISYS, A.; STELLA, C. D. 2010. Vamos brincar? São Paulo, Edições SESC SP, 190p.

LAWSON, B. What designers know. Oxford: Architectural Press, 2004.

LEONTIEV, A. N. Os princípios psicológicos da brincadeira pré-escolar. In: Vygostky, L.S.; Luria, A. R; Leontiev. A. N. (Orgs.), Linguagem, desenvolvimento e aprendizagem. São Paulo: Moraes, 2010.

MARGOLIN, V., MANZINI, E. Stand up for democracy. 2017. Disponível em:<http://www.democracy-design.org/open-letter-stand-up-democracy/>. Acesso em: $22 \mathrm{dez}$. 2017.

MAZZILLI, Clice de Toledo Sanjar. Arquitetura Lúdica: criança, projeto e linguagem. Estudos de espaços infantis educativos e de lazer. Tese de Doutorado em Arquitetura e Urbanismo. São Paulo, Faculdade de Arquitetura e Urbanismo da Universidade de São Paulo, 2003.

MOORE, Deborah. 'The teacher doesn't know what it is, but she knows where we are': young children's secret places in early childhood outdoor environments, 2015. International Journal of Play, 4:1, 20-31, DOI: 10.1080/21594937.2014.925292.

MORRISEY, A., SCOTT, C., WISHART, L. Infant and toddler responses to a redesign of their childcare outdoor play space. Children, Youth and Environments, n. 25(1), p. 29-56 2015.

NASCIMENTO, Andrea Zemp Santana. A criança e o arquiteto: quem aprende com quem? 
Dissertação de Mestrado em Arquitetura e Urbanismo. São Paulo, Faculdade de Arquitetura e Urbanismo da Universidade de São Paulo, 2009.

$\mathrm{NICHOLSON,} \mathrm{J.} \mathrm{et} \mathrm{al.} \mathrm{Listening} \mathrm{to} \mathrm{children's} \mathrm{perspectives} \mathrm{on} \mathrm{play} \mathrm{across} \mathrm{the} \mathrm{lifespan:} \mathrm{children's} \mathrm{right}$ to inform adults' discussions of contemporary play. International Journal of Play, vol. 3, Iss. 2, p. 136-156, 2014.

PASCHOALIN, Daniel Morais. O horizonte da conversão: concepções do processo projetual arquitetônico. 2012. Tese de Doutorado. Universidade de São Paulo.

RODRIGUES, Laís; CAMPELLO, Silvio Barreto. Relação entre o design emocional e a teoria da aprendizagem: ferramentas para o estudo da interação da criança com o brinquedo. Blucher Design Proceedings, v. 2, n. 2, p. 1131-1136, 2015.

SCHÖN, Donald A. The reflective practitioner: how professionals think in action. 1983.

SEVALDSON, Birger. The Integrated conglomerate approach: A suggestion for a generic model of design research. In: DURLING, D.; FRIEDMAN, K. (org.). Doctoral Education in Design: Foundations for the Future. France: Stanffordshire University Press, p.163-170, 2000.

SNODGRASS, A.; COYNE, R. Is design hermeneutical? In: SNODGRASS, A.; COYNE, R. Interpretation in architecture. Design as a way of thinking. London: Routledge, 1997/2006.

THANE, L. 2005. Experimental Playground Project. Disponível em: <https://www.youtube.com/watch?v=g3swGPa5rp0>. Acesso em: 16, out., 2016.

VAN PATTER, G. K., PASTOR, E. Innovation Methods Mapping: de-mystifying 80+ years of innovation process design. New York: Humantific Publishing, 2016.

WILLET, R. Everyday game design on a school playground: children as bricoleurs. International Journal of Play, 4:1, p. 32-44, 2015.

WINNICOTT, Donald Woods. O brincar e a realidade. Trad. José Octávio de Aguiar Abreu e Vanede Nobre. Rio de Janeiro: Imago, 2005. 